\title{
PENGARUH KAPITALISME PADA KELOMPOK SOSIALITA: MENELAAH HEDONISTIC CONSUMERISM DI KALANGAN HERMES LOVERS
}

\author{
Devita Prinanda \\ Ilmu Hubungan Internasional, Fakultas Ilmu Sosial dan Ilmu Politik \\ Universitas Muhammadiyah Malang \\ devita.prinanda@gmail.com
}

\begin{abstract}
Consumerism is a development of consumption terms. Consumption is fundamental to meeting people's needs while consumerism is an act of excessive consumption. People who consume desires from needs are called hedonistic consumerism. This phenomenon is an economic habit, especially among the elite. A thick bedonistic culture will be a negative impression because it relates to something that is excessive. The capitalism system underlies people's behavior to become consumers who are hedonistic.

Branded bags are a product of capitalism. The existence of this product is favored by certain circles because the price reaches hundreds of millions. This bag collector is spread all over the world and the great collectors bave a dependency on these luxury bags and consume them continuously. However, this hedonism activity does not only have a negative impact. From a bobby of collecting luxury bags can be used as a profitable investment and even across national borders. Furthermore, the writer will also explain alternative assumptions for a socialistic lifestyle that is hedonistic.
\end{abstract}

Keywords: Konsumerisme, Capitalism, Hermes, Hedonistic Consumerism, Investation

\begin{abstract}
Abstrak
Konsumerisme merupakan perkembangan dari term konsumsi. Konsumsi merupakan pemenuban kebutuban masyarakat secara mendasar sedangkan konsumerisme merupakan tindakan konsumsi yang berlebihan. Masyarakat yang mengkonsumsi keinginan dari pada kebutuhan disebut sebagai hedonistic consumerism. Fenomena ini menjadi kebiasaan ekonomi terutama di kalangan elit. Budaya hedonistik kental akan kesan negatif karena berbubungan dengan sesuatu yang berlebihan. Sistem kapitalisme mendasari perilaku masyarakat untuk menjadi konsumen yang bersifat hedonistic.

Tas branded merupakan produk kapitalisme. Keberadaan produk ini digemari oleh kalangan tertentu karena harganya yang mencapai ratusan juta. Kolektor tas ini tersebar di selurub dunia dan bebatnya para kolektor ini memiliki ketergantungan akan tas mewah tersebut dan mengkonsumsinya secara terus menerus. Namun, kegiatan yang bersifat hedonisme ini ternyata tidak hanya membawa dampak negatif. Dari sebuah hobi mengkoleksi tas mewah dapat dijadikan investasi yang menguntungkan dan babkan bingga lintas batas negara. Selanjutnya penulis juga akan memaparkan asumsi alternatif untuk gaya bidup sosialita yang bersifat hedonistik.
\end{abstract}

Kata kunci: Konsumerisme, Kapitalisme, Hermes, Hedonistic Consumerism, Investasi

\section{PENDAHULUAN}

Sistem kapitalisme yang menuntun bentuk dan perilaku konsumen melalui budaya dan keinginan. Ini merupakan manipulasi untuk penentuan konsumsi yang ditanamkan kepada masyarakat. Fenomena mengkonsumsi melebihi keinginan terjadi paska perang dunia ke II yang kemudian dinamakan dengan Hedonistic Consumerism. Evolusi dalam sistem ekonomi mengantarkan kita pada sistem ekonomi modern termasuk juga kapitalisme di dalamnya. Interaksi 
ekonomi mengatur adanya pertukaran ekonomi yang mempermudah organisasi kapitalis modern berkembang. Kapitalisme beranggapan bahwa aktor ekonomi ada karena untuk memenuhi kepuasan individu.

Konsumerisme untuk kalangan yang menkonsumsi barang mewah terbatas untuk kalangan elit. Dimana budaya, bentuk, dan kebiasaan ini telah berhasil mengaplikasikan kapitalisme modern. Konsumerisme menjadi identik dengan status sosial. Individu mengkonsumsi barang yang jauh dari kebutuhan hidup seharusnya dan bahkan melebihi nalar. Seperti mengkonsumsi kopi dengan harga sangat tinggi sampai kebutuhan yang terlihat seperti tas, baju, sepatu, dan jam tangan mewah. Apabila kalangan bawah mengkonsumsi hal yang dibutuhkan untuk bertahan hidup, lain hal dengan kalangan atas yang mengkonsumsi untuk memenuhi kepuasaan dan pengakuan status sosial. Konsumerisme yang seperti ini kemudian lebih dikenal dengan hedonistic consumerism.

Kapitalisme modern berjalan lurus dengan kegiatan konsumerisme. Adanya ketergantungan antara produksi dan konsumer yang membuat interaksi ini terus berlanjut menjadi budaya. Konsumerisme juga meningkat seriring adanya produksi secara besar-besaran. Jadi, budaya hedonistic consumerism dibangun oleh supply dan demand dari konsumer dan produsen tidak hanya salah satu. Aktor yang terlibat diantaranya Multinational Coorporations (MNC), negara, organisasi internasional, dan individu sebagai konsumer.

Dengan berkembangnya aktor ekonomi maka berkembang pula mass production dan konsumerisme. Perkembangan ekonomi modern yang seperti ini mengarah pada status sosial. Masyarakat menjadi terkotak-kotakkan berdasarkan keinginan akan mengkonsumsi sesuatu. Masyarakat juga terbagi atas partisipasi mereka dalam pasar baik sebagai konsumen maupun produsen.Dengan adanya ekonomi global tidak hanya membuat mass production mudah tersebar karena akses ekonomi namun juga membuat para pelaku hedonistic consumerism meluas. Budaya ini menjadi kompleks seiring dengan pergembangan globalisasi(Migone, 2004).

\section{HERMES LOVERS SEBUAH BUDAYA HEDONISME DI KALANGAN ELIT}

Pada awalnya tas Hermes diproduksi untuk digunakan bangsawan Eropa pada abad 18. Pencipta pertamanya, Thierry Hermes mendapatkan pujian dan penghargaan atas karyanya. Selanjutnya penerus usaha Thierry yaitu anaknya Charles Emile melanjutkan bisnis ini untuk memproduksi tas bagi penunggang kuda. Kemudian, pada abad 19 usaha ini berlanjut dengan memproduksi tas dengan koleksi yang lebih banyak. Abad ini mengantarkan Hermes Freres (nama perusahaan pada saat itu) memasuki pasar Amerika Serikat dan memproduksi tas, parfum, dasi, dan lainlain. Brand ini kemudian disukai kaum tertentu karena produksinya yang sangat digemari. Namun karena dari awal terbentuknya sudah ditujukan pada kaum bangsawan, maka semakin berkembang Hermes semakin membentuk pola konsumsi kaum elit untuk produknya(Fimela, 2014).

Harga tas Hermes yang dikonsumsi banyak kaum sosialita mencapai 500-800 juta rupiah. Bahkan untuk edisi tertentu bisa mencapai milyaran rupiah. Seperti pada Hermes tipe Birkin Himalayan dapat dilelang dengan harga mencapai 2,5 milyar sampai dengan 6 milyar rupiah. Kemahalan harga tas tersebut dikarenakan proses pembuatannya yang sangat teliti dan memakan proses yang cukup lama serta bahan yang terbuat dari kulit buaya asli dengan lapisan emas atau berlian pada aksesorisnya (Kartikawati, 2015). Pola konsumerisme pada level tinggi ini mengarah pada sifat hedonistik yang dimiliki pada kelompok tersebut. Dengan harga yang tidak seharusnya untuk membeli sebuah tas, mereka membelinya dengan tujuan kepuasan batin. Tas kini tidak hanya dilihat sebagai fungsinya namun lebih kepada bentuk, merk, warna, motif, dan lain-lain. Sehingga nilai estetika yang lebih diungguli ketimbang fungus. Tas juga menunjukkan identitas sosial pemakai.

Dengan harga tas yang melebihi harga tas normal, menunjukkan bahwa sifat konsumerisme dalam hal ini hanya bisa dilakukan oleh kaum elit. Produk Hermes menjadi penentu status sosial para konsumen. Banyak brand lain seperti channel, Louis vuitton, Prada dan sebagainya yang memiliki nilai jual yang tinggi namun dengan produk hermes yang produksinya hanya bagi kalangan tertentu dan jumlah produksinya tidak terlalu banyak 
membuat para sosialita memburu untuk menjadikannya 'jinjingan' mewah untuk dipamerkan. Terlebih, mereka yang berada dalam satu golongan elit apabila melihat yang lain membawa hermes sedangkan dia tidak akan merasa inferior dan merasa status sosialnya lebih rendah.

Wanita menjadi sasaran utama kapitalis untuk memasarkan produk mereka. Metropolitan dan modernisme yang memuculkan adanya kaum sosialita yang banyak anggotanya adalah para wanita. Sosialita melambangkan kemakmuran suatu kelompok. Kapitalisme mengkontruksi kelompok sosialita agar mengalami reduksi kebutuhan dari kebutuhan utama yang mendasar menjadi terinterpretasikan (Yulfianto, 2014). Sebagai contoh konsumsi tas Hermes menjadi kewajiban bagi setiap sosialita ketimbang mengkonsumsi tas produk lokal produksi tanggulangin.

Kapitalisme menggeser makna dari sosialita itu sendiri. Sosialita dulunya bermakna kumpulan orang kaya yang dermawan dan suka mengadakan kegiatan sosial. Memang dulunya kaum sosialita hanya teruntukkan bagi bangsawan Eropa atau keluarga kerajaan, tapi gelar sosialita tidak hanya berdasarkan lingkup kerajaan yang diwariskan namun juga prestasi sosial individu atau kelompok tersebut. Dulunya, kelompok sosialita memperoleh kemudahan akses untuk melakukan sesuatu seperti menonton pertujukan dan sebagainya. Namun, dengan produk kapitalisme yang tersebar dimana-mana dibuktikan dengan brand yang diproduksi dengan harga tinggi dan disebar secara massive di pasar global. Perluasan makna sosialita yang sekarang menjadi identik dengan sekumpulan orang yang berasal dari keluarga konglomerat, pengusaha, kaya, pejabat, atau golongan artis. Sosialita kini menjadi hasil konstruksi masyarakat yang identik dengan sekelompok orang elit yang mengkonsumsi barang-barang mahal dan berkumpul untuk mengadakan arisan dan sebagainya. Termasuk bagi kumpulan sosialita kolektor tas Hermes.

Produk ini dikonsumsi tidak hanya satu negara saja. Konsumen tas Hermes sudah mendunia dan disetiap negara pasti terdapat pecinta produk ini. Globalisasi menyebarkan global kapitalisme yang menyebabkan sifat hedonistik bagi seseorang. Globalisasi juga memfasilitasi mudahnya persebaran produkproduk Hermes melalui broker tas disetiap negara. Selain melalui broker tas, juga banyak acara lelang tas Hermes yang dilakukan di banyak negara. Seperti di Hongkong pada januari 2015 terdapat acara lelang tas Hermes tipe Birkin yang berhasil terlelang dengan harga 2,8 Milyar Rupiah (Tribun News, 2015). Di New York, selebriti Kim Kadarshian juga melelang koleksi tas Hermesnya di Heritage Auctionguntuk di jual dengan harga ratusan juta (Metro TV, 2013).

Di singapura terdapat kolektor tas Hermes yang dikatakan sebagai kolektor terbanyak di Asia. Jamie Chua seorang sosialita di negaranya yang memiliki sampai ribuan Hermes yang bisa dikatakan tidak murah(Riza, 2015). Koleksi Chua bisa disetarakan dengan koleksi Hermes milik Victoria Beckham. Produksi Hermes sudah menguasai pasar Asia namun tetap pada kalangan tertentu. Di Indonesia produk ini hanya bisa di konsumsi oleh artis seperti Syahrini, Angel Elga, dan beberapa sosialita istri para pebisnis. Chua sendiri merupakan mantan istri pengusaha asal Indonesia. Kepemilikan khusus ini membuktikan ke eksklusifan dari pemilik Hermes yang mengarah pada sifat bedonistic concumerism hanya bisa dilakukan oleh kaum tertentu.

Dalam kasus ini lebih banyak terlihat bagaimana pengaruh dari sistem kapitalisme terhadap individu sebagai pelaku konsumerisme. Namun, individu ini terkoneksi dengan mudah dengan kolektor dan penjual di negara lain untuk mendapatkan produk yang mereka mau. Sedangkan dampak yang lebih terlihat adalah bagi masyarakat itu sendiri seperti dampak psikologis dan dampak terhadap perekonomian.

Walaupun terdapat beberapa kritik bagi pengkonsumsi dan produsen tas Hermes yang menyebar sebagai isu internasional. Isu yang tersebar seperti penggunaan kulit buaya secara massive untuk memproduksi sebuah tas. Berita yang tersebar terkait perusahaan ini adalahpenganiayaan terhadap buaya yang akan di ambil kulitnya. Berita ini merugikan Hermes karena sampai membuat penyanyi Jane Birkin ingin menarik namanya yang digunakan untuk salah satu tipe tas Hermes(VOA, 2016).Isu internasional yang tersebar menyatakan bahwa penggunaan kulit perut buaya untuk tas Hermes didapatkan dengan cara penyiksaan terhadap buaya yang baru berumur 1 tahun. Untuk satu tas seperti tipe Kelly dan Birkin produksi Hermes, membutuhkan sekitar 3 buaya (Lumbantobing, 2015). Namun, hal tersebut tidak digubris oleh hermes lovers dan tetap memburu seri birkin dengan harga fantastis. 
Devita Prinanda: Pengarub Kapitalisme Pada Kelompok Sosialita ...

Fenomena ini berlanjut pada dampak psikologis dari pengkoleksi tas tersebut. Karena harga tas yang dapat dikatakan seharga rumah, para hedonis ini bersifat mengagungkan sebuah barang sederhana yaitu tas. Hal ini dibuktikan dengan pengaruh psikologis pada salah satu kolektor Hermes yang mengatakan bahwa lebih baik dirinya terkena hujan dari pada tasnya yang terkena hujan. Manusia jika sakit dapat diobati dengan mengkonsumsi obat, jika tas akan mengakibatkan harganya jatuh (Jawa Pos, 2014). Dampak psikologis yang lebih parah adalah terdapat salah satu kolektor tas Hermes yang lebih memilih membeli tas ratusan juta dan tidak memiliki mobil dan memilih menggunakan taksi sebagai alat transportasi (Vlrorida, 2011).

\section{Pemanfaatan Hedonistic Consumerism Menjadi Investasi sebagai Alternatif untuk Tidak Hanya Menjadi Konsumen}

Komunitas sosialita yang menjadikan hobi mengoleksi tas branded ini sebagai usaha dan investasi di Indonesia adalah Himpunan Pengusaha Branded Orientik (Hiperbratik). Para anggota kelompok ini yang terdiri dari sosialita pada awalnya tertarik untuk mengoleksi tas branded dengan model klasik. Mereka sampai bunting tas langsung ke produsen tas mewah di negara-negara Eropa seperti Prancis, Italia, dan Inggris (Fajriana, 2015)

Bermula dari kesamaan hobi mengkonsumsi tas mewah yang kebanyakan ber-merk Hermes, komunitas ini berdiri sebagai wadah saling bertukar pikiran mengenai hobi tersebut. Kemudian banyaknya penjual tas branded palsu diluaran menggugah komunitas ini merubah konsep komunitasnya menjadi kelompok penjual tas yang asli. Komunitas ini berkembang seiring banyaknya konsumer yang tersebar di seluruh Indonesia bahkan sampai negara tetangga seperti Singapura (Kusuma, 2013).

Seorang pecinta Hermes, menjadikan hobinya dalam sebuah buku. Dari sebuah kegiatan hedonis juga dapat dijadikan hal-hal positif dengan mendirikan komunitas, usaha, sampai dengan mencetak buku. Buku berjudul "Hermes Temptation" menjelaskan mengenai panduan pembelian, perawatan, dan budaya kolektor Hermes di Indonesia dan di luar negeri (Vlrorida, 2011). Awalnya mereka mengkoleksi tas Hermes berdasarkan catalog yang dipunyai. Hobi membeli Hermes di banyak seri dan warna untuk dipadu padankan dengan pakaian yang digunakan. Namun, berlanjut menjadi sebuah usaha dengan memfasilitasi penjualan Hermes melalui bbm kepada pecinta Hermes lainnya. Sehingga kemudian lahir sebuah buku mengenai pengalaman penulis dan lingkungan sekitar hermes lovers.

Dalam buku hermes temptation yang ditulis oleh salah satu kolektor dan pebisnis tas Hermes di Indonesia diulas mengenai bagaimana gaya hidup bagi masyarakat yang mengkonsumsi tas ini. Harga tas yang beragam menentukan status sosial pemilik tas tersebut. Buku ini ditulis oleh Fitria Yusuf dan Alexandra Dewi dalam bahasa inggris dengan tujuan dapat dipasarkan secara internasional. Keduanya tidak hanya sebagai penulis buku, namun juga sebagai broker tas Hermes yang menjual produk asli baru maupun second(Ekasari, 2011).

Selain di Indonesia, pemanfaatan tas Hermes sebagai penghasil keuntungan yang berlipat juga terjadi pada seorang wanita asal Florida. Melalui kegiatan lelang, seorang wanita tersebut berani membeli harga mahal untuk tas yang diinginkannya hinga mencapai 1,8 milyar rupiah. Namun, kemudian ia kembali melelangkan tastas hermes koleksinya dengan harga yang jauh lebih menguntungkan. Hal ini dapat dilakukan karena mengingat jumlah tas Hermes yang diproduksi sangat terbatas (Sindo, 2011). Yang menjadi kontroversi adalah tas Hermes ini tidak diproduksi secara masal. Jumlah produksinya sangat terbatas, sehingga membuat harganya sangat mahal. Menjadi suatu fenomena baru bahwa tidak melakukan mass production pada suatu barang tertentu bisa lebih menguntungkan para kapitalis.

\section{Asumsi Alternatif Bagi Pelaku Hedonistic Consumerism}

Di era industri ini sedikit susah bagi masyarakat untuk tidak mengkonsumsi keinginan yang melebihi kebutuhan dasar. Kapitalisme terus membangkitkan minat masyarakat untuk menjadi konsumen aktif terhadap produk mereka. Sehingga kelangkaan bukan lagi penyebab adanya kegiatan ekonomi supply dan demand, namun mengarah kepada menyajikan apa yang menjadi permintaan masyarakat untuk dikonsumsi lebih. Sebaliknya, bisa juga kapitalisme menyajikan produk yang akhirnya meningkatkan minat masyarakat untuk mengkonsumsi walaupun bukan kebutuhan dasar.(Etzioni, 2004). Masyarakat menjadi pecandu barang-barang mewah seperti layaknya kaum sosialita yang terus-menerus membeli tas Hermes walaupun sebenarnya tas lain yang jauh 
lebih murah memiliki fungsi yang sama. Dalam kata lain adalah mereka terpengaruh oleh brand atau merk tertentu dan kemudian menjadi konsumen yang bersifat addictive.

Untuk menjauhkan sifat hedonistic consumerism memang tidak mudah. Namun berkaca pada kehidupan milyader seperti Bill Gates yang memilih pergi dengan busana sederhana merupakan contoh bahwa tidak semua budaya hedonis menjangkit kalangan elit. Sifat seperti ini dikatakan sebagai voluntary simplicity oleh Amitai Etzioni (Etzioni, 2004).

Asumsi yang harus dibangun adalah bagaimana untuk hidup bahagia tanpa mengutamakan uang dan materi. Budaya ini bisa dibangun melalui memilih untuk mendapatkan penghasilan yang tidak banyak namun memiliki banyak waktu dengan keluarga sehingga kebahagian akan materi terdistraksi dan terdominasi oleh kebahagiaan kumpul bersama keluarga. Apabila individu tersebut memang memiliki penghasilan yang tinggi bisa dilakukan simpanan untuk jangka panjang daripada dipergunakan untuk menuruti sifat 41edonistic untuk mengkonsumsi barang mewah. Budaya konsumerisme bisa menurun dari orang tua. Sebagai contoh sederhana agar tidak menanamkan budaya 41edonistic pada anak adalah dengan memberikan quality time lebih untuk bersama ketimbang memberikan uang yang banyak untuk mencukupi kebutuhan.

Anti konsumerisme mengajarkan untuk lebih baik meninggalkan segala hal yang ada di kota besar dan metropolitan. Tinggal di daerah pedesaan yang jauh dari akses media, kelompok sosialita, dan sebagainya untuk meninggalkan pola hidup kelas atas. Kegiatan ini dinamakan simple living untuk mendapatkan kehidupan yang lebih sederhana.

Konsumerisme dapat terjadi akibat pengaruh iklan suatu produk atau tekanan masyarakat sekitar (Etzioni, 2004). Seperti di Indonesia, seorang wanita malu apabila rekannya memakai Hermes sedangkan dia hanya memakai brand kelas menengah seperti Channel, Prada, dan lain-lain. Padahal, produk yang mereka bilang kelas menengah juga mencapai harga puluhan dan ratusan juta. Namun, Hermes merupakan produk yang lebih unggul karena jumlah produksi dan harganya yang jauh lebih mahal. Hermes yang dipakai wanita lain memberikan tekanan pada wanita lainnya untuk menggunakan barang yang lebih sama. Tekanan sosial ini berdampak pada keinginan untuk mengkonsumsi.
Untuk menjawab fenomena ini dibutuhkan mind setatas kebahagiaan itu sendiri. Karena sebuah penelitian menunjukkan bahwa tingkat kebahagian di wilayah yang pendapatannya lebih rendah dari pada masyarakat kelas atas. Kebahagiaan tidak hanya bisa didapatkan dari belanja barang-barang di luar kebutuhan dasar. Etzioni memberikan ide untuk lebih melakukan hal lain selain belanja yang dapat memberikan kepuasan, kebahagiaan, dan berharga (Etzioni, 2004). Hal-hal seperti berlibur bersama dengan keluarga ke tempat sederhana seperti pedesaan, mengadakan aktivitas sosial untuk membantu kaum miskin, mengunjungi keluarga dan berkumpul bersama, dan sebagainya bisa sebagai alternative untuk menghindari bedonistic consumerism.

Mengacu pada pernyataan diatas dapat dibuktikan bahwa pendapatan yang tinggi tidak berbanding lurus dengan kebahagiaan yang di dapat. Sayangnya, masyarakat yang berada pada kelompok ekonomi atas mulai berfikir untuk hidup dalam simple living atau menganut voluntary simplicity merupakan kelompok yang kebahagiaan atas materinya terpenuhi. Mereka sudah menjadi penganut bedonistic consumerism terlebih dahulu. Jadi sifat dasar 41edonistic41ic mendahului dan kemudian membuat kelompok ini sadar akan kebahagian untuk hidup sederhana(Etzioni, 2004).

Untuk para Hermes Lovers untuk menjadi voluntary simplicity seharusnya mulai menggunakan material yang dipunya untuk mengadakan kegiatan sosial dari pada digunakan untuk membeli tas dengan harga milyaran. Tas memang kebutuhan penting karena fungsinya yang harus dimiliki terutama bagi wanita. Untuk mendapatkan simple living diharapkan untuk membeli tas sesuai dengan kebutuhan dan bukan keinginan atau kepuasan batin. Motif dan bentuk tas dipilih sesuai dengan kenyamanan dan jumlah barang yang di bawa dan bukan dari taburan emas yang terdapat pada aksesoris tas.

\section{SIMPULAN}

Budaya mengkonsumsi secara berlebihan terhadap sesuatu yang sebenarnya tidak dibutuhkan merupakan budaya 41edonistic. Budaya ini merupakan bentukan sistem kapitalisme yang sudah tersebar secara global. Namun, pada kalangan tertentu dapat memanfaatkan sifat 41edonistic mereka menjadi sebuah investasi yang besar. Dalam lingkup internasional, konsumerisme terlihat dipaksakan 
Devita Prinanda: Pengaruh Kapitalisme Pada Kelompok Sosialita ...

oleh pelaku kapitalisme. Globalisasi mempermudah para kapitalis menyebarkan liberal ekonomi yang berpengaruh pada konsumsi yang berlebihan. Sehingga banyak yang dirugikan dalam kegiatan ini seperti alam, dampak psikologis, dan perubahan ekonomi yang semakin menguntungkan kaum kapitalis. Sebagai masyarakat internasional seharusnya lebih bijak dalam mengkonsumsi dan mampu menjadikan budaya hedonistic menjadi keuntungan.

Alternatif lain untuk membendung budaya ini adalah dengan kembali hidup sederhana menjauhkan pemikiran kepuasaan atas barang mewah dan hal yang bersifat materi. Mementingkan aspek kebahagiaan yang lebih bermakna seperti kumpul bersama keluarga. Ini menjadikan pilihan bagi kelompok elit untuk dapat melakukan hidup dengan simple living dan menjauhkan budaya bedonistic consumerism.

\section{DAFTAR PUSTAKA}

Ekasari, E. 2011. Hermes Temptation, Kisah Penjual Tas Hermes di Indonesia. Retrieved from Detik.com: wolipop.detik.com/read/2011/11/30/14561 5/1779216/233/hermes-temptation-kisahpenjual-tas-hermes-di-indonesia

Etzioni, A. 2004. The Post Affluent Society. Review of Social Economy, VOL. XII No. 3.

Fajriana, M. 2015. Gaya Hidup Sosialita Indonesia, Hunting Sampai Ke Eropa. Retrieved from Liputan6:http://m.liputan6.com/lifestyle/rea d/2300969/gaya-hidup-sosialita-indonesiahunting-sampai-ke-eropa

Fimela. 2014. Menengok Sejarah Merk Hermes. Retrieved from Fimela: http://www.fimela.com/life/menengoksejarah-merk-hermes-1409176.html

Jawa Pos. 2014. Mereka yang Mesra dengan Tas-Tas Berharga Seolah-olah Tenteng Rumah. Retrieved from Jawa Pos Lifestyle: http://www2.jawapos.com/baca/artikel/263 3/mereka-yang-mesra-dengan-tas-tasberharga

Kartikawati, E. 2015. Kemewahan Tas Hermes Birkin Himalayan yang Jadi Sengketa di Pengadilan. Retrieved from Wolipop Lifestyle: http://wolipop.detik.com/read/2015/08/28 /172321/3004131/233/kemewahan-tashermes-birkin-himalayan-yang-jadi-sengketadi-pengadilan

Kusuma, D. R. 2013. Cegah Beredar Hermes Abalabal, Kolektor Tas Bermerek Bentuk Komunitas.
Retrieved from Detik Finance: http://www.yiela.com/view/3048572/cegah -beredar-hermes-abal-abal-kolektor-tasbermerek-bentuk-komunitas

Lumbantobing, A. 2015. Harga yang Harus Dibayar untuk Kemewahan. Retrieved from liputan http://hiburan.metrotvnews.com/read/2013 /04/17/147356/Kim-Kardashian-Lelang-

Dua-Tas-Hermes-Mewahnya

Metro TV. 2013. Kim Kardashian Lelang Dua Tas Hermes Mewahnya. Retrieved from Metro TV News:

http://hiburan.metrotvnews.com/read/2013 /04/17/147356/Kim-Kardashian-Lelang-

Dua-Tas-Hermes-Mewahnya

Migone, A. 2004. Hedonistic Consumerism: From Want-Satisfaction to WhimSatisfaction. CGPE Working Paper .

Riza. 2015. Jamie Chua, Sosialita Asal Singapura, Punya Tas Hermes Terbanyak Se-Asia. Retrieved from Seleb Update: http://selebupdate.com/sosialitasingapura/4665

Sindo. 2011. Hermes Birkin, Tas Termahal di Dunia. Retrieved from Okezone Lifestyle: http://lifestyle.okezone.com/read/2011/12/ 12/29/541169/hermes-birkin-tas-termahaldi-dunia

Tribun News. 2015. Tas Hermes Terjual Milyaran Rupiah Dalam Lelang. Retrieved from Tribun Pekanbaru: http://pekanbaru.tribunnews.com/2015/06/ $03 /$ tas-hermes-terjual-milyaran-rupiah-dalamlelang

Vlrorida, Y. 2011. Fitria \& Dewi, Jutawan Berkat Jualan Tas Mewah via BBM. Harga Tas Setengah Miliar, Diperlakukan bak Bayi. Retrieved from Radar Bangka: http://www.radarbangka.co.id/rubrik/detail / features/1919/fitria-dan-dewi-jutawanberkat-jualan-tas-mewah-via-bbm-harga-tassetengah-miliar-diperlakukan-bak-bayi.html

VOA. 2016. Hermes Berunding dengan Birkin Terkait Nama Tas. Retrieved from Voice of America: http://www.voaindonesia.com/content/her mes-berunding-dengan-birkin-terkait-namatas/2936151.html

Yulfianto, A. 2014. Sosialita, Konsumerisme dan Status Sosial. Retrieved from Kompasiana: http://www.kompasiana.com/adeyulfianto/s osialita-konsumerisme-dan-statussosial_54f68bcaa33311a17c8b4fcc 